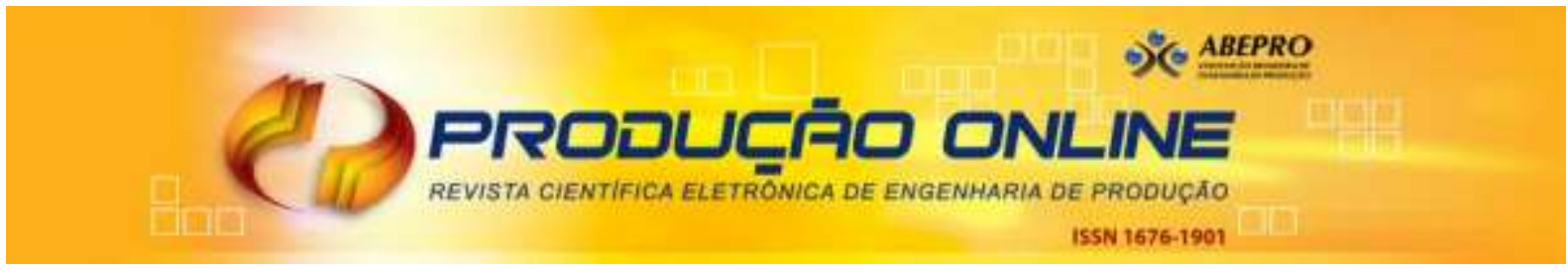

\title{
REDUÇÃO DE VARIABILIDADE NO PROCESSO DE PRODUÇÃO DA ALVENARIA ESTRUTURAL: PADRÃO TÉCNICO E KIT COMPLETO
}

\section{VARIABILITY REDUCTION OF STRUCTURAL MASONRY PRODUCTION PROCESS: TECHNICAL STANDARD AND COMPLETE KIT}

\author{
Camilla Araújo Coelho Oliveira* E-mail: camillacoelho25@hotmail.com \\ Débora de Gois Santos* E-mail: deboragois@yahoo.com.br \\ *Universidade Federal de Sergipe (UFS), São Cristóvão, SE
}

Resumo: Para tornar mais eficaz o processo de gestão empregado na construção civil, tem-se buscado utilizar, como sustentação, os princípios da Construção Enxuta, já que propiciam a potencialização do desempenho do planejamento. A variabilidade é considerada, por diversos autores, como a principal causa para a ocorrência de perdas. A padronização pode ser utilizada como um meio de obtenção da redução da variabilidade, já que possibilita um melhor controle da produção e deve ser aplicada desde o início do serviço, garantindo que todos os recursos necessários - kit completo - para sua realização estejam disponíveis e em condições ideais e padronizadas. Assim, o objetivo principal deste trabalho foi identificar os tipos de variabilidade no processo de produção da alvenaria estrutural por meio do padrão técnico e do uso do kit completo. Para isto, foi realizado um estudo exploratório de múltiplos casos aplicando observação em campo e registro de dados. Identificou-se que os tipos de variabilidade ocorriam por se distanciar do padrão desejado. Além disso, as interferências pertencem à categoria preparação do trabalho, que considera que os itens do kit completo e as variabilidades decorrentes das interferências trouxeram, como consequências, perdas do tipo making-do. Sendo assim, espera-se, com este diagnóstico, contribuir para o melhoramento do desempenho desse processo.

Palavras-chave: Redução de variabilidade. Padronização. Kit completo.

Abstract: To improve the efficiency of construction management process, Lean Construction principles have been employed since they allow planning performance enhancement. Variability, is considered by several authors as the main cause for the occurrence of losses. The standardization can be used to reduce variability, because it allows a better control of production and can be applied since the beginning of the process to ensure that all the necessaries recourses - complete kit - are available, and in ideal and standardized conditions. Thus, the main objective of this paper was to identify the types of variability in the masonry structural production process through technical standard and use of complete kit. For this, an exploratory study of multiples cases was carried out, using field observation and data recording. It was identified that the types of variability occurred when there was distance from the desired pattern. In addition, interferences occurred in the category of work preparation to complete kit. In addition, the interferences belong to the preparation category of the work, which considers that the items of the complete kit and the resulting variabilities brought, as a consequence, losses of the making-do type. Thus, it is expected, with this diagnosis, to contribute to the improvement of the performance of this process.

Keywords: Variability reduction. Standardization. Complete kit. 


\section{INTRODUÇÃO}

A construção civil é uma indústria complexa, pois sua produção envolve a idealização ou concepção, o planejamento e a construção geralmente de um produto único (GROSSKOPF et al., 2013).

Com o intuito de minimizar esses problemas, introduziu-se a industrialização na Indústria da Construção Civil, a partir do uso de elementos pré-moldados e da modulação (KOSKELA, 1992). Além disso, iniciou-se a aplicação de uma nova filosofia, denominada de Produção Enxuta, cujo objetivo principal era a identificação e posterior eliminação das perdas, sendo então possível a redução dos custos (SHINGO, 1996b).

Os conceitos dessa nova filosofia começaram a ser aplicados na construção após um estudo feito por Lauri Koskela em 1992 e têm como objetivo analisar todo o fluxo dos materiais - desde a matéria-prima até o produto final -, considerando as atividades que não agregam valor (transporte, espera e inspeção) e as que agregam. Para isso, foram desenvolvidos onze princípios, sendo a redução da variabilidade um deles.

Nesensohn et al. (2014) reconhecem as dificuldades das construtoras em implementar modelos gerenciais, como a construção enxuta. Existem duas razões para desejar a redução da variabilidade do ponto de vista gerencial. A primeira relaciona-se com a uniformidade do produto, indo além das especificações exigidas, buscando-se, dessa forma, a melhoria da qualidade do material. A segunda relaciona-se com a duração da atividade, pois a variabilidade tende a aumentar as atividades que não agregam valor (KOSKELA, 1992).

Segundo Nascimento e Santos (2013), existem três tipos de atividades executadas pelos funcionários. A primeira é a atividade produtiva, ou seja, que agrega valor ao produto final; a segunda é a atividade auxiliar, que não agrega valor ao produto final, mas são essenciais para a execução dos serviços; e a terceira é a atividade improdutiva, que também não agrega valor ao produto.

Para Ronen (1992), uma das formas de se obter a redução da variabilidade é garantindo que todos os itens necessários para a execução de uma atividade estejam disponíveis antes do início da mesma. Koskela (2004) ressalta que esses itens devem estar nas condições ideais e padronizadas. 
A primeira justificativa para a escolha da alvenaria estrutural para 0 desenvolvimento deste trabalho se pauta na observação de que a elevação de empreendimentos em alvenaria estrutural acarreta impacto ambiental e financeiro, devido à geração de resíduos. Além do mais, esse serviço é o de maior relevância no custo da obra. Uma segunda justificativa é que a alvenaria estrutural é um sistema construtivo que naturalmente requer a aplicação da padronização (FRANCO, 1992).

Considerando a existência de tipos de variabilidade na produção e a prática da alvenaria estrutural, que por sua concepção é um sistema padronizado, questiona-se se é possível utilizar um pacote de pré-requisitos (kit completo) para reduzir a variabilidade na construção?

Diante disto, o objetivo deste trabalho foi identificar os tipos de variabilidade no processo de produção da alvenaria estrutural por meio do padrão técnico e do uso do kit completo.

Deste modo, o método de trabalho compreendeu pesquisa bibliográfica e de estudo de casos múltiplos em canteiros de obras de alvenaria estrutural, para buscar evidências que respondam ao problema de pesquisa. Para tal, procedeu-se a realização de visitas técnicas e entrevistas e a análise de documentos. Sendo assim, o artigo está estruturado em introdução, revisão bibliográfica, metodologia de pesquisa, resultados (descrição do objeto de pesquisa e dos estudos de caso) e conclusões.

\section{REVISÃO DA LITERATURA}

Para que pudesse alcançar a redução dos custos através da eliminação das perdas existentes no processo produtivo, Shingo (1996a) dividiu a estrutura da produção em dois fluxos - processo e operação - como mostra a Figura 1. O processo, eixo vertical, é definido por Shingo (1996a, p. 26) como "o caminho pelo qual a matéria-prima é transformada em produto". Já a operação, eixo horizontal, consiste em "ações efetuadas sobre o material pelos trabalhadores e máquinas". 0 diagrama da linha de balanço (Figura 2) pode também ser utilizado como uma ferramenta que auxilie a análise dos processos e operações na construção civil (ISATTO; ZUCHETTI, 2014). Moura e Heineck (2014) também associam a redução 
da variabilidade no processo de produção de edifícios com o uso da linha de balanço.

Figura 1 - A estrutura da produção

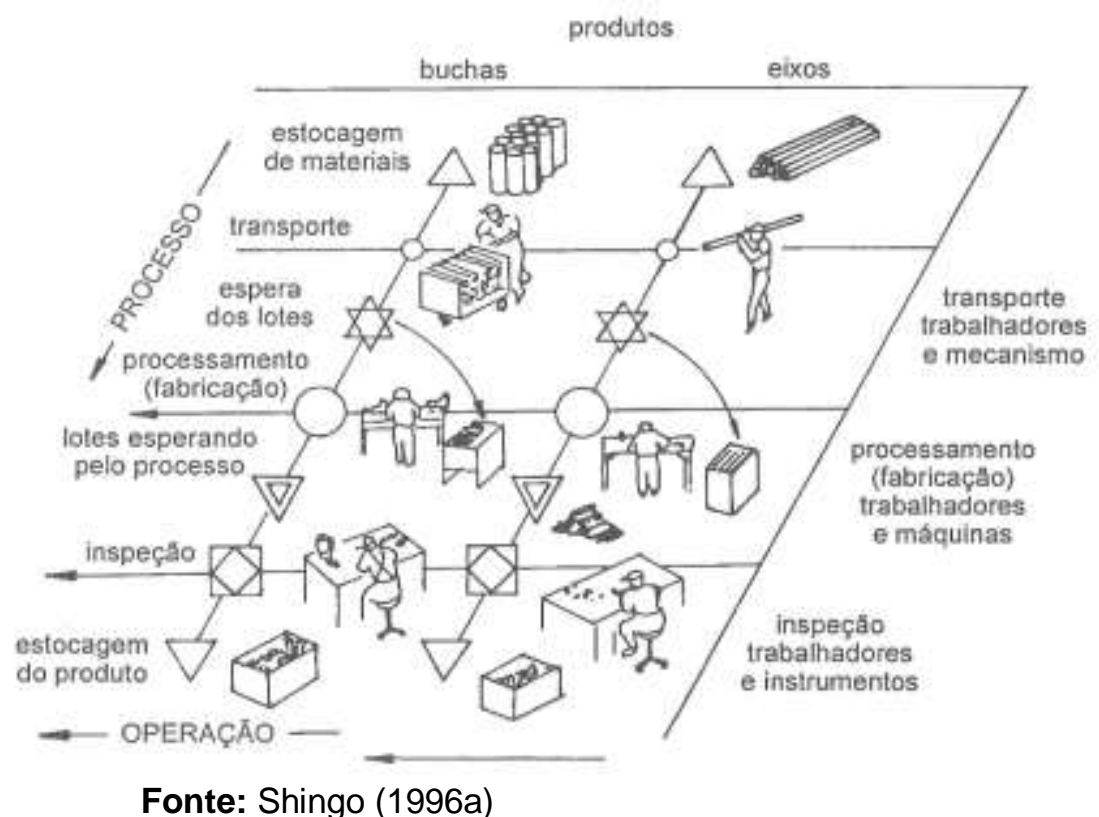

Figura 2 - Processos e operações em um diagrama de linha de balanço

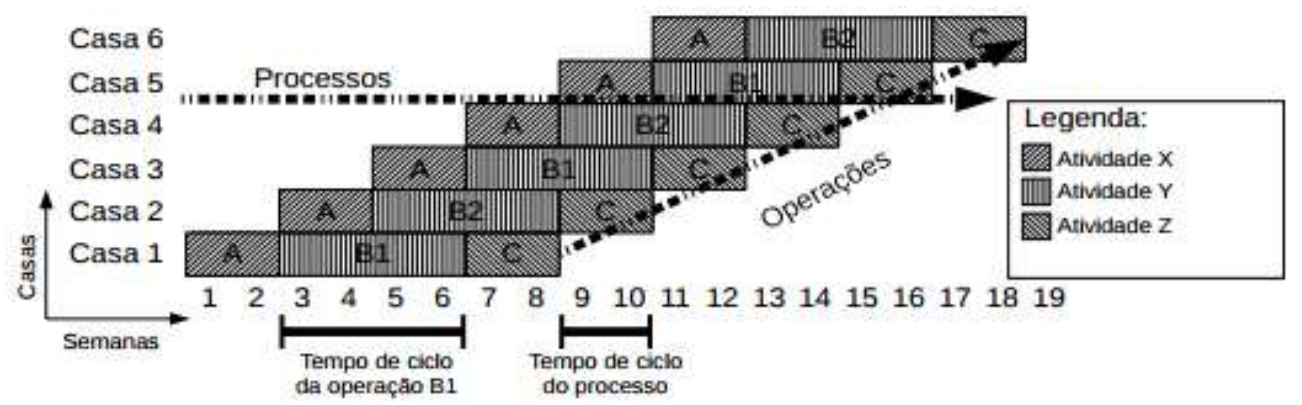

Fonte: Isatto e Zuchetti (2014)

A partir da compreensão da estrutura de produção, percebeu-se que a melhoria do processo poderia ocorrer de duas formas. A primeira está relacionada com a engenharia de valor, podendo ser entendida, segundo Howell (2011), como tudo aquilo realizado que auxilia a atingir o que foi proposto pelo cliente, além de possuir extrema influência na eliminação de perdas do tipo processamento. A segunda forma de melhoria está ligada com a melhoria dos métodos de fabricação através da tecnologia utilizada na fabricação (LIKER; HOSEUS, 2009).

Os estudos na Toyota permitiram encontrar sete classes de perdas distintas durante o processo de produção: defeitos (nos produtos), excesso de produção, 
estoques de mercadorias, processamento desnecessário, movimento (de pessoas), transporte (de mercadorias) e espera. A criação dessa lista proporcionou a visualização da perda que geralmente não é notada por já ter se tornado aceita como parte do trabalho diário (SHINGO, 1996b e OHNO, 2004).

A partir da difusão dos conhecimentos obtidos e por meio da nova forma de produzir do STP, outras indústrias iniciaram a aplicação da nova ideia denominada de Produção Enxuta, que tem como objetivo principal, segundo Tonin e Schaefer (2013), reduzir as perdas de material e de mão de obra.

Koskela (1992), ao abordar os conceitos da Produção Enxuta na construção civil, criou um modelo de processo da Construção Enxuta. Assim, Koskela (1992) desenvolveu onze princípios:

- Reduzir a porcentagem de atividades que não agregam valor;

- Aumentar o valor de saída através de uma análise sistemática das necessidades do cliente;

- Reduzir a variabilidade;

- Reduzir o tempo de ciclo;

- Simplificar, minimizando o número de passos, partes e vínculos;

- Aumentar a flexibilidade de saída;

- Aumentar a transparência do processo;

- Focar no controle completo do processo;

- Introduzir a melhoria contínua no processo;

- Equilibrar a melhoria de fluxo com a melhoria de conversão; e

- Benchmarking.

O princípio destacado neste trabalho foi o princípio da redução da variabilidade, que pode ser chamado de redução de incerteza ou aumento da previsibilidade. Koskela (2004) afirma ainda que a principal causa para a ocorrência de perdas no sistema de produção é a variabilidade.

Entretanto, nem toda a variabilidade pode ser anulada, sendo algumas necessárias para atender às necessidades do cliente, como, por exemplo, a solicitação de mudança do projeto por parte do cliente, de acordo com Isatto et al. 
(2000). Santos et al. (2002a) afirmam que existem dois tipos de variabilidade: de fluxo e de processamento.

A variabilidade de fluxo ocorre quando a variabilidade de uma estação de trabalho interfere em outra que a antecedeu ou em uma atividade subsequente. Dessa forma, o tempo de processamento acaba sendo uma parcela mínima, ao compará-lo com todo o fluxo, já que o tempo gasto com espera - material, mão de obra, maquinário, etc. - é muito maior (SANTOS et al., 2002b). Já a variabilidade de processamento, de acordo com Hopp e Spearman (1996), é aquela que limita a continuação da produção, comprometendo a eficiência do sistema produtivo, como, por exemplo, a quebra de um equipamento. Segundo Isatto et al. (2000), os tipos de variabilidade ocorridos durante o processo de produção podem ser subdivididos em:

- Variabilidade nos processos anteriores - relaciona-se com os fornecedores do processo, como, por exemplo: blocos cerâmicos com grandes variações dimensionais.

- Variabilidade no próprio processo - ocorre durante o processo de produção, como, por exemplo: a variabilidade da duração de uma determinada atividade após a conclusão de vários ciclos.

- Variabilidade na demanda - depende dos desejos dos clientes, tanto os internos como também os externos, durante todo o processo produtivo, como, por exemplo: a modificação em partes do projeto por parte dos clientes externos.

O presente artigo voltou-se para a variabilidade nos processos anteriores e no próprio processo.

Algumas desvantagens são identificadas quando existem altos níveis de variabilidade no processo, de acordo com Hopp e Spearman (1996), como, por exemplo, a ocorrência de work-in-progress, que na construção civil é calculada pelo número de tarefas que estão sendo executados no mesmo momento (SACKS et al., 2010). Já a divisão segmentada de responsabilidades, a falta de sincronização dos fluxos de trabalho e o sistema de bônus individualista resultam na alta variabilidade do processo de operações (SANTOS et al., 2002a). Uma outra desvantagem causada pelo fenômeno da variabilidade na produção é a ocorrência de making-do, 
já que a variabilidade traz uma indisponibilidade de uma entrada padrão (KOSKELA, 2004).

Making-do é considerada a oitava categoria de perda e foi proposta por Koskela (2004). Este tipo de perda é típica da indústria da construção e pode ser acrescentada à lista de Shingo (1996b) e Ohno (2004). Essa nova perda ocorre quando uma tarefa inicia ou continua sem que todos os recursos necessários para a sua realização estejam disponíveis (KOSKELA, 2004). Sommer (2010) destaca que o making-do pode também ser definido como a ação de gerenciar com o que se tem disponível, ou seja, improvisar. Este conceito teve como base outro conceito - kit completo -, proposto por Ronen (1992), definido como a junção de componentes, documentos, desenhos e informações necessárias para completar um conjunto, subconjunto ou um processo.

Fazinga (2012) afirma que, por intermédio da adoção da padronização para determinado pacote de trabalho, é possível reduzir a variabilidade no processo, além de estabilizar o desempenho no mesmo. Para Morgan (2008), a padronização possui a capacidade de sistematizar a produção, dando estabilidade ao processo, ou seja, possibilitando a repetição, promovendo o cumprimento regular do tempo de ciclo, a melhoria da produtividade, bem como a redução do custo e do lead time.

Boggio (1995) acrescenta que a padronização possibilita a redução da variabilidade nos processos gerenciais. De acordo com Leão et al. (2014a), para que seja possível aplicar o que foi definido na etapa de padronização e também possibilitar a identificação e remoção da ocorrência de making-do, faz-se necessário haver uma adequada gestão da produção, através da realização de planejamentos de médio e curto prazo.

Howell et al. (2011) afirmam que um planejamento detalhado e baseado nos princípios da Construção Enxuta possibilita o envolvimento dos que estão mais próximos da linha de produção e maximiza o desempenho do planejamento como um todo e não somente das partes. Ao introduzir os conceitos da nova filosofia de produção - Produção Enxuta - no planejamento, tem-se como resultado o Sistema Last Planner ${ }^{\mathrm{TM}}$ de Controle de Produção.

Ballard (2000) define o Sistema Last Planner ${ }^{\mathrm{TM}}$ (LPS) de Controle da Produção como uma filosofia e um conjunto de ferramentas que facilitam a implementação de um controle mais efetivo. Estudos como o de Leão et al. (2014b) 
mostram que, ao utilizar um modelo de controle da qualidade integrado com 0 Sistema Last Planner ${ }^{\mathrm{TM}}$ em canteiro de obras, é possível identificar os pacotes de trabalho informais executados no canteiro de obras.

Koskela (2000) sugere realizar o controle da produção e melhorar a produção em si, de modo que a variabilidade existente possa ser eliminada. Para Campos (2004), todo o sistema de produção deve ter como principal objetivo o atendimento das necessidades do cliente. No entanto, esse objetivo só poderá ser atingido por meio da prática do controle da qualidade na organização e na melhoria de padrões. É importante ressaltar que o conceito do controle da qualidade sofreu mudanças ao longo do tempo, passando do enfoque na qualidade do produto final para o enfoque sobre o controle do processo produtivo, e, por fim, para a garantia da qualidade de todo o ciclo de produção, que inclui a etapa de concepção do produto.

Por sua vez, Shingo (1996b) afirma que a melhoria do processo pode acontecer de duas formas. A primeira está relacionada com a melhoria do produto através da Engenharia de Valor, que possui extrema influência na eliminação de perdas do tipo processamento. A segunda forma de melhoria está ligada com o aprimoramento dos métodos de fabricação através da tecnologia utilizada na fabricação.

Para Koskela (1999), Hamzeh et al. (2008) e Sacks et al. (2010), o LPS contribui para a redução da variabilidade dos fluxos de trabalho e também para o aumento da produtividade nos canteiros de obra. Além disso, é uma poderosa ferramenta para a redução da ocorrência do making-do, já que tem como regra não iniciar uma tarefa sem que todas as entradas estejam disponíveis (KOSKELA, 2004).

A não disponibilidade de recursos em tempo hábil à execução acarreta em paralisação da obra pela falta de recursos. A análise de restrições é uma das áreas de conhecimento de interesse para o estudo da descontinuidade nos processos de produção, que trata de fatores que restringem o fluxo de produção nos locais de desenvolvimento de processos, sendo aplicado na construção civil através do uso do sistema Last Planner ${ }^{\mathrm{TM}}$ (SANTOS, 2004). Tendo como base diferentes autores, a referida autora dividiu as restrições em: de recursos, de informações, de processo, temporais e espaciais, estratégicas e de empreendimento.

Bernardes (2001), Machado (2003), Sommer (2010) e Fireman (2012) citam exemplos práticos de restrições que ocorrem nos canteiros de obras, como, por 
exemplo, falta de projeto ou detalhamento do mesmo, falta de recursos suficientes para a execução de determinados serviços, mão de obra pouco qualificada ou não treinada, equipamentos quebrados ou inadequados às tarefas, falta de instalações provisórias necessárias para a execução do serviço, falta de terminabilidade dos serviços predecessores etc.

No contexto da análise de restrições, surgem as atividades que contribuem para a melhoria dos sistemas produtivos na construção civil, proporcionando o controle dos processos e evitando interrupções no fluxo de produção. Essas atividades podem receber a denominação de "boas práticas", pois visam eliminar ou reduzir, direta ou indiretamente, os fatores que gerem interrupções nos diversos processos e fluxos de produção (MESQUITA, 2014).

Santos (2004), a partir do estudo das causas de interrupção em obras, classificou ainda essas atividades em nove categorias: acesso, projeto, preparação do trabalho, conferência do trabalho, conflito espacial, sequenciamento, proteção dos operários, proteção dos processos e programação de obra. De acordo com Mesquita (2014), quando as atividades de boas práticas, na forma de antecipações gerenciais, não são aplicadas no momento certo, ocorrem falhas. Essas falhas implicam em deixar de adotar uma melhoria no processo, podendo, ainda, gerar o risco de uma interrupção no processo.

A partir dos estudos realizados por Machado (2003) e Santos (2004) - que tiveram como objetivo facilitar a identificação de ações gerenciais que evitassem as interrupções nos processos construtivos - bem como de Koskela (2000), Sommer (2010) propôs sete categorias de perdas por making-do que buscam expor aquilo que deve ser analisado para que o trabalho não seja interrompido, conforme apresentado no Quadro 1. 
Quadro 1 - Categorias de perdas por making-do

\begin{tabular}{|c|l|}
\hline CATEGORIAS & \multicolumn{1}{|c|}{ DEFINIÇÃO } \\
\hline Acesso/mobilidade & $\begin{array}{l}\text { Relativo ao espaço, meio ou forma de posicionamento de quem } \\
\text { executa as tarefas }\end{array}$ \\
\hline Ajuste de componentes & $\begin{array}{l}\text { Artifícios para uso de componentes não adequados à } \\
\text { realização das tarefas }\end{array}$ \\
\hline Área de trabalho & $\begin{array}{l}\text { Refere-se à bancada de trabalho ou área de apoio durante as } \\
\text { atividades realizadas }\end{array}$ \\
\hline Armazenamento & $\begin{array}{l}\text { Organização de materiais ou componentes em locais não } \\
\text { preparados para o seu recebimento }\end{array}$ \\
\hline Equipamentos/ferramentas & Criados ou adaptados para uso durante as atividades \\
\hline Instalações provisórias & $\begin{array}{l}\text { Criados ou adaptados para uso de água e eletricidade durante } \\
\text { as atividades }\end{array}$ \\
\hline Proteção & Forma de uso dos sistemas de proteção \\
\hline
\end{tabular}

Fonte: Sommer (2010)

Fireman (2012) propôs um refinamento no método proposto por Sommer (2010), ao incluir uma nova categoria de perda por making-do, definida como sequenciamento, que se refere à alteração na ordem de produção de um determinado processo, ou o rearranjo da sequência de ataque.

Contribuindo para a identificação das perdas por making-do, Sommer (2010) apresenta, através do Quadro 02, os itens propostos para a identificação da origem das perdas, sua descrição e classificação, sendo os sete primeiros itens correspondentes às pré-condições estabelecidas por Koskela (2000).

Alguns estudos (Coelho, 2009; Sommer, 2010; Fireman et al., 2013; Grosskopf, 2013; Leão, 2014; Mesquita, 2014), realizados com o intuito de verificar a ocorrência do making-do na construção civil, apontaram que esse tipo de perda pode ser a causa principal de outras perdas, como problemas de qualidade, retrabalho e work-in-progress (WIP).

Para Formoso et al. (2017), a identificação das perdas do tipo making-do concedem uma maior compreensão das causas do baixo desempenho dos projetos de engenharia. Entretanto, esse tipo de perda é mais fácil de ser detectado quando realizado por observadores experientes e que possuam conhecimento do procedimento padrão do processo executivo (LEÃO et al., 2016). 
Quadro 2 - Natureza das perdas por making-do

\begin{tabular}{|c|c|c|}
\hline NATUREZA & DESCRIÇÃO & CLASSIFICAÇÃO \\
\hline Informação & $\begin{array}{l}\text { Projetos, planos, estudos e procedimentos que fornecem } \\
\text { toda informação necessária para a execução dos pacotes de } \\
\text { trabalho não estão disponíveis, não são claros, estão } \\
\text { incompletos ou são desconhecidos }\end{array}$ & Método \\
\hline $\begin{array}{l}\text { Materiais e } \\
\text { componentes }\end{array}$ & $\begin{array}{l}\text { Não são previstos, disponíveis ou adequados à atividade } \\
\text { com qualidade, quantidade e dentro das especificações de } \\
\text { projeto e normas }\end{array}$ & Materiais \\
\hline Mão de obra & $\begin{array}{l}\text { Não está disponível em número que atenda os planos, pouco } \\
\text { qualificada ou não foi treinada }\end{array}$ & Mão de obra \\
\hline $\begin{array}{l}\text { Equipamentos ou } \\
\text { ferramentas }\end{array}$ & $\begin{array}{l}\text { Indisponíveis, não funcionam ou não são adequados às } \\
\text { tarefas }\end{array}$ & Máquina \\
\hline Espaço & $\begin{array}{l}\text { Não há acesso à área de trabalho, circulação ou } \\
\text { armazenamento de materiais }\end{array}$ & Meio \\
\hline \begin{tabular}{|c|} 
Serviços \\
interdependentes
\end{tabular} & $\begin{array}{l}\text { Atividades com alta interdependência comprometem a } \\
\text { execução das tarefas subsequentes }\end{array}$ & Meio \\
\hline $\begin{array}{l}\text { Condições } \\
\text { externas }\end{array}$ & Vento, chuva ou temperaturas externas & Meio \\
\hline Instalações & $\begin{array}{l}\text { Instalações provisórias não atendem as necessidades para } \\
\text { execução dos pacotes de trabalho, incluindo: instalações } \\
\text { elétricas e hidráulicas provisórias }\end{array}$ & Meio \\
\hline
\end{tabular}

Fonte: Sommer (2010)

Ainda como causa do making-do, Formoso et al. (2011) argumentam que esse tipo de perda é consequência de falhas no planejamento, fazendo com que o operário encontre alguma forma de realizar a tarefa, através do improviso, com os recursos que estão disponíveis. Para Fireman et al. (2013), essas perdas podem ainda estar relacionadas à falta de terminalidade das tarefas.

Segundo Santos e Santos (2017), os impactos da "falta de terminalidade" e do "retrabalho" são provenientes de processos inconclusos ou concluídos com má qualidade e constituem o trabalho inacabado na produção.

Em resumo, Koskela (2004) considera seis principais impactos das perdas por making-do: diminuição da produtividade, desmotivação, perda de material, retrabalho, redução da segurança e redução da qualidade. Ao considerar a nova categoria de perda, sequenciamento, um outro impacto é identificado: falta de terminabilidade (FIREMAN, 2012).

\section{METODOLOGIA}

Estabeleceu-se uma metodologia dividida em três partes: revisão da literatura, pesquisa de campo e tabulação de dados, de modo a identificar os tipos de 
variabilidade que ocorrem no processo de produção da alvenaria estrutural, como também as interferências geradas por essa ocorrência de variabilidade.

Após a revisão bibliográfica, a escolha da amostra deu-se a partir do cadastro, fornecido pela CAIXA ECONÔMICA FEDERAL, de empresas que tinham empreendimentos de alvenaria estrutural financiados pelo banco no estado de Sergipe. A lista continha 38 (trinta e oito) empresas diferentes, porém apenas 4 (quatro) possuíam os critérios necessários para a escolha da empresa e do empreendimento:

- Empresas de médio ou grande porte.

- Obras em alvenaria estrutural na fase de elevação da alvenaria.

- Empreendimentos pertencentes a empresas distintas.

- Estágio da obra em fase de finalização da alvenaria estrutural.

Segundo Yin (2001), um estudo deve estar firmado em diversas fontes de evidências para dar confiabilidade aos resultados da pesquisa. Dessa forma, foram utilizadas as seguintes fontes de evidências neste estudo exploratório:

- Análise de documentos (procedimento operacional de elevação de alvenaria, fichas de verificação de serviço, fichas de verificação de material, consulta a projetos arquitetônico, de modulação e estrutural).

- Entrevistas semiestruturadas realizadas com gerentes de obras, encarregados ou mestres de obras e com o responsável pelo almoxarifado.

- Observação direta - trata dos acontecimentos em tempo real.

- Registros fotográficos.

Para as entrevistas, foi utilizado um checklist para obras que utilizavam bloco cerâmico e, outro para as que utilizavam concreto adaptado de Santos (2008). O checklist adotado se baseia nas normas técnicas que tratam de alvenaria estrutural, como a NBR 6136 (ABNT, 2014), NBR 15270-1 (ABNT, 2005a), NBR 15270-2 (ABNT, 2005b), NBR 15270-3 (ABNT, 2005c), NBR 15812-2 (ABNT, 2010) e NBR 15961-2 (ABNT, 2011). Além do checklist, utilizou-se também um roteiro com a 
finalidade de coletar todas as informações necessárias. Todas as visitas foram acompanhadas do estagiário responsável pela torre ou pelo serviço.

Foi utilizada ainda uma planilha eletrônica contendo as seguintes informações: nome da atividade, detalhamento da atividade, vantagem de seu uso, princípios enxutos relacionados à atividade, tipos de perdas evitadas ou não, categorias de atividades facilitadoras em que a atividade se enquadra, nível hierárquico e proposta de melhoria. Existia uma planilha por empreendimento pesquisado e por tipo de atividades (pontos positivos ou boas práticas; atividadesfalhas) correlacionada aos tipos de variabilidade.

A partir das visitas, foi possível obter a compreensão do processo produtivo de elevação da alvenaria estrutural utilizado por cada empresa. Como consequência, foi elaborada, para cada empreendimento, uma lista com os pontos positivos ou boas práticas e, outra com os pontos negativos ou frágeis encontrados.

Com a conclusão da tabulação dos dados obtidos, foi feito um cruzamento entre os dados, que resultou em gráficos do Excel, demonstrando, assim, quais os tipos de variabilidade que mais ocorriam nas obras; as consequências pela ocorrência da variabilidade; as boas práticas encontradas que possibilitavam a redução da variabilidade e das perdas do tipo making-do; e o comparativo entre o padrão estabelecido por norma para a alvenaria estrutural (processos anteriores e o processo de elevação) e o realizado na obra.

\section{RESULTADOS E DISCUSSÕES}

Após a conclusão da formação da base de dados foi possível elaborar gráficos que relacionam o que foi visto em campo ao que é definido na teoria. A apresentação dos resultados se inicia com gráficos que comparam o padrão do processo de produção da alvenaria estrutural descrito nas normas reguladoras com o que foi visto em campo. Em seguida, são apresentados gráficos, elaborados a partir da descrição das obras, quanto aos pontos positivos ou boas práticas e aos pontos negativos ou frágeis. 


\subsection{Caracterização das obras pesquisadas}

Durante 0 estudo exploratório nos quatro empreendimentos, foram observados os serviços que compreendem a elevação da alvenaria, ou seja, da marcação da primeira fiada até a fiada de respaldo.

As empresas selecionadas para o estudo exploratório possuíam características adequadas aos critérios estabelecidos na metodologia deste trabalho. Os empreendimentos possuíam algumas características em comum, como, por exemplo: os empreendimentos A, B e C participavam do projeto Minha Casa Minha Vida do Governo Federal; todos os empreendimentos eram classificados pelo Programa Brasileiro de Qualidade Produtiva no Habitat (PBQP-H), sendo nível "B" o empreendimento $D$ e os demais, nível "A"; todos os empreendimentos foram executados utilizando o sistema construtivo de alvenaria estrutural parcialmente armada e com laje maciça. As demais características das empresas e empreendimentos estão descritas nos parágrafos subsequentes.

O empreendimento A, localizado na cidade de Aracaju, é composto por duas torres, tendo cada uma sete pavimentos e oito apartamentos por pavimento, com áreas de aproximadamente $60 \mathrm{~m}^{2}$ cada apartamento, totalizando assim 112 apartamentos.

Por sua vez, o empreendimento B, localizado na cidade de Aracaju, é composto por cinco torres, cada uma com oito pavimentos e oito apartamentos por pavimento, totalizando 320 apartamentos. Cada apartamento possui aproximadamente $45 \mathrm{~m}^{2}$.

O empreendimento $\mathrm{C}$, localizado na cidade de Barra dos Coqueiros, é composto por seis torres, cada uma com quatro pavimentos e oito apartamentos por pavimento, sendo quatro apartamentos com dois quartos e os outros quatro apartamentos com três quartos, totalizando 192 apartamentos. A área aproximada dos apartamentos de dois quartos é de $43 \mathrm{~m}^{2}$ e os de três quartos é de $55 \mathrm{~m}^{2}$.

Por fim, o empreendimento $D$, localizado na cidade de Barra dos Coqueiros, é composto por dezesseis torres, tendo cada uma quatro pavimentos (térreo e três pavimentos tipo ${ }^{1}$ ) e seis apartamentos por pavimento, contendo o pavimento térreo:

\footnotetext{
1 Pavimento tipo é o pavimento que apresenta repetição do layout interno de suas unidades habitacionais, ou seja, são pavimentos que têm suas características de layout internos repetidos. No exemplo, são três pavimentos com as mesmas características.
} 
dois apartamentos de três quartos, dois apartamentos de dois quartos e um apartamento de um quarto; já nos pavimentos tipo, 4 apartamentos de três quartos e dois apartamentos de dois quartos, totalizando 464 unidades habitacionais.

Os empreendimentos $A$ e $D$ foram executados com bloco cerâmico, porém o cintamento do empreendimento $D$ foi executado com bloco de concreto. Os empreendimentos B e C foram executados com bloco de concreto.

Após aplicação do checklist da norma técnica a cada empreendimento, além de execução de registros fotográficos, entrevistas e elaboração de lista descritiva de pontos positivos ou frágeis, foi possível resumir as informações por empreendimentos, transformar em uma frequência de ocorrência e, assim, pontuar comparativamente todos os empreendimentos envolvidos no estudo.

\subsection{Verificação de cumprimento de itens de norma que podem interferir na redução da variabilidade}

Esta análise de dados foi referente ao cumprimento dos itens de norma de procedimento executivo que regulamentam a execução da alvenaria estrutural de blocos cerâmicos e blocos de concreto.

O gráfico da Figura 3 mostra o quanto as empresas estão cumprindo os padrões estabelecidos para o produto - recebimento e armazenamento do bloco. Pelo gráfico, percebe-se que nenhuma das empresas cumpriu $100 \%$ do padrão estabelecido pelas normas no que se refere ao recebimento dos blocos, ocorrendo assim grande variabilidade nesse aspecto. Já no que se refere ao armazenamento dos blocos, observa-se que apenas uma obra atingiu 100\%, porém duas das obras visitadas não cumpriram nenhuma das exigências da norma nesse aspecto. 
Figura 3 - Exigências das normas para o material bloco cerâmico ou de concreto

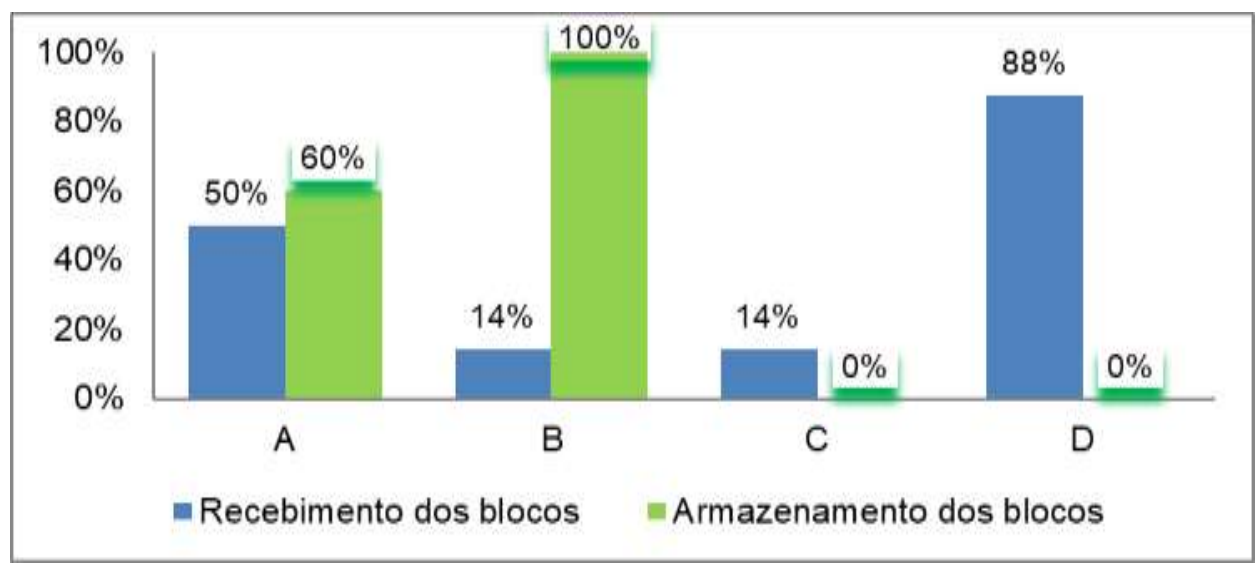

Fonte: Elaborado pelos autores

O gráfico da Figura 4 mostra quanto as empresas estão cumprindo dos padrões estabelecidos como requisitos para se cumprir antes do início da elevação e das atividades necessárias para a implantação (marcação), o que é importante para reduzir a variabilidade nos processos anteriores. Observa-se que todas as quatro empresas cumpriram mais de $65 \%$ dos requisitos a serem executados antes do início da elevação propriamente dita e mais de $55 \%$ para as atividades de implantação.

A implantação passa a ser o local de atuação do kit completo e de possibilidade de ocorrência de making-do, por se tratar de etapa anterior ao início do processo construtivo. Observa-se que essas situações retratadas nos gráficos das Figuras 3 e 4 relacionam-se com variabilidade nos processos anteriores ao processo executivo.

Figura 4 - Exigências das normas para as atividades anteriores à elevação da alvenaria

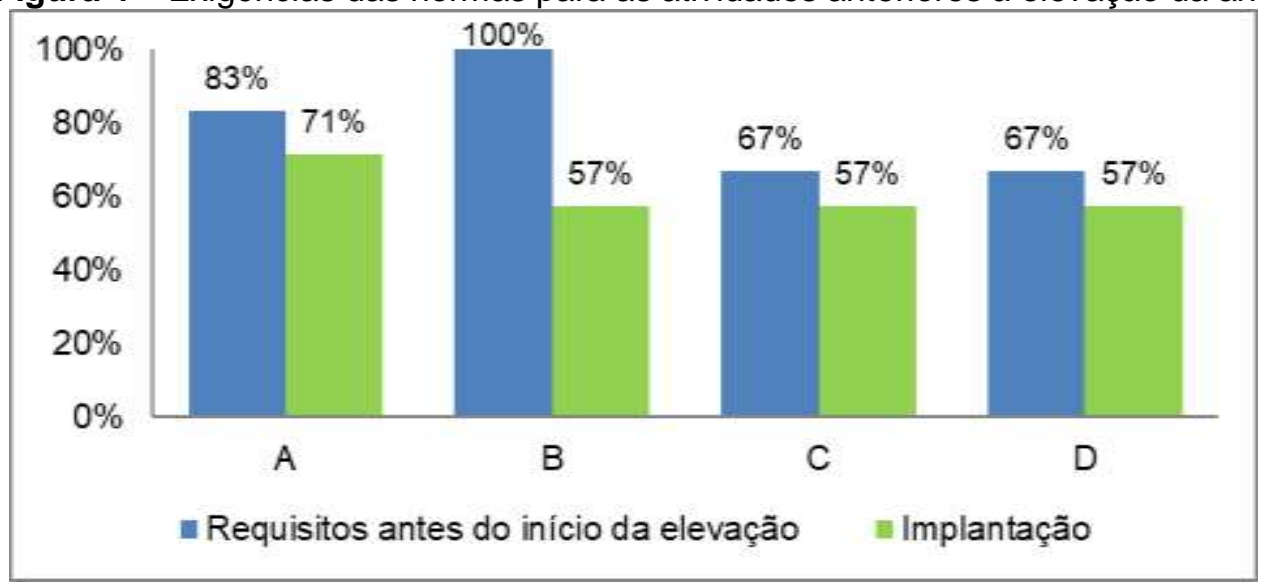

Fonte: Elaborado pelos autores 
O gráfico da Figura 5 apresenta o quanto as empresas estão cumprindo os padrões estabelecidos em relação ao processo construtivo referente à elevação da alvenaria estrutural e aos detalhes construtivos. Com relação a esses dois itens, percebe-se que as empresas cumpriram em média $86 \%$ dos requisitos referentes à execução da alvenaria e todas cumpriram 100\% dos itens que cabiam aos detalhes construtivos, considerando as peculiaridades de cada obra.

Os itens referentes à execução da alvenaria e a detalhes construtivos estão relacionados com espessura de junta, forma de amarração etc. Esses itens determinam um padrão a ser seguido, já que existem limitações de normas para os mesmos. Se esses itens são aplicados de forma correta, seguindo sempre o padrão estabelecido, reduz-se a variabilidade.

Figura 5 - Exigências das normas para o processo de produção de elevação de alvenaria

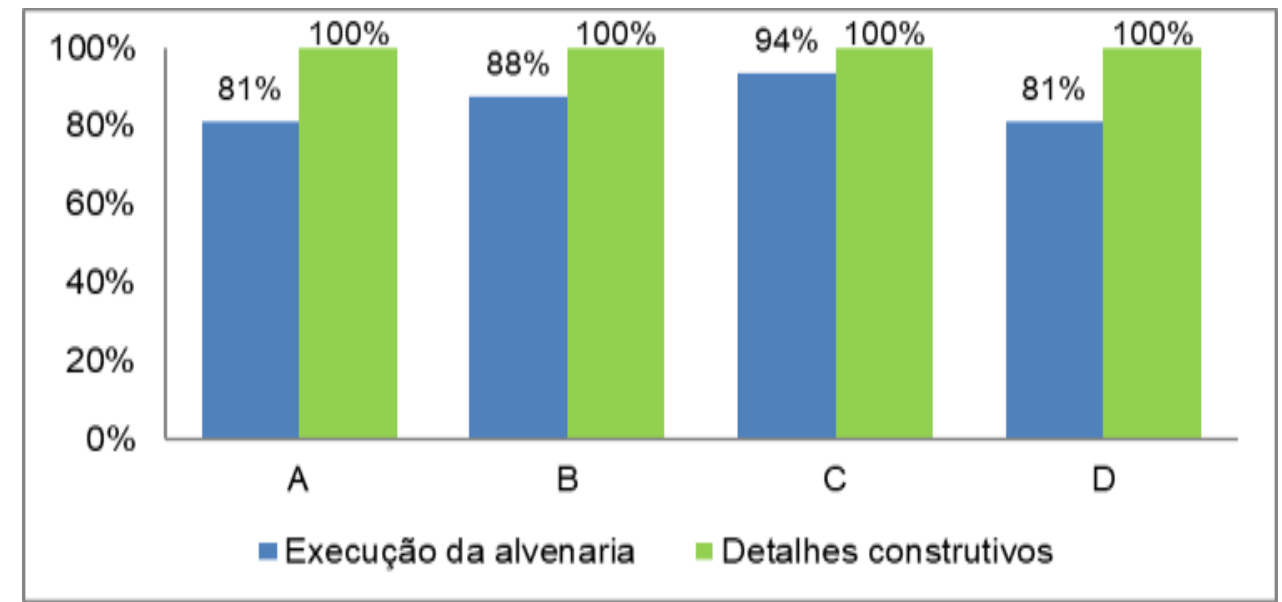

Fonte: Elaborado pelos autores

Em resumo, o recebimento dos blocos de modo adequado ocorreu em apenas $41,5 \%$ para as obras pesquisadas. Para o armazenamento dos blocos, esta percentagem foi inferior, 40\%. Quanto aos requisitos antes do início da elevação, constatou-se execução adequada destes em $79,25 \%$ dos casos. Já os itens referentes à implantação foram pontuados em $60,5 \%$, execução da alvenaria em $86 \%$ e detalhamentos construtivos em $100 \%$ das obras.

Pode-se inferir, com isso, que as empresas preocupam-se mais com a execução e o detalhamento da execução da alvenaria do que com os cuidados para o recebimento do material que dará forma a esta alvenaria, ou seja, a preocupação volta-se para reduzir variabilidade no próprio processo mais do que nos processos 
anteriores, sendo um contrassenso, dado o impacto deste último tipo de variabilidade no primeiro tipo.

Ao cumprir parte dos requisitos referentes ao processo construtivo, as ações nos canteiros de obras contribuem para a redução da variabilidade no processo, porém deixam a desejar nos itens que antecedem o processo de produção em si. Os dados confirmam a importância da preparação das atividades, de forma que sejam disponibilizados todos os sete fluxos necessários para a realização da tarefa na quantidade ideal e com as características preestabelecidas, com o intuito de evitar a ocorrência da variabilidade nos processos anteriores e no próprio processo.

\subsection{Atividades positivas (boas práticas)}

A Figura 6 representa, em termos de porcentagem, a relação entre os pontos positivos ou boas práticas encontradas nas obras visitadas com os onze princípios de Koskela (1992). Percebe-se que a maioria das boas práticas aplicadas nas obras, $23 \%$ delas, está diretamente relacionada com a redução da variabilidade.

Figura 6 - Quantificação percentual das Boas Práticas em relação aos Princípios da Construção Enxuta

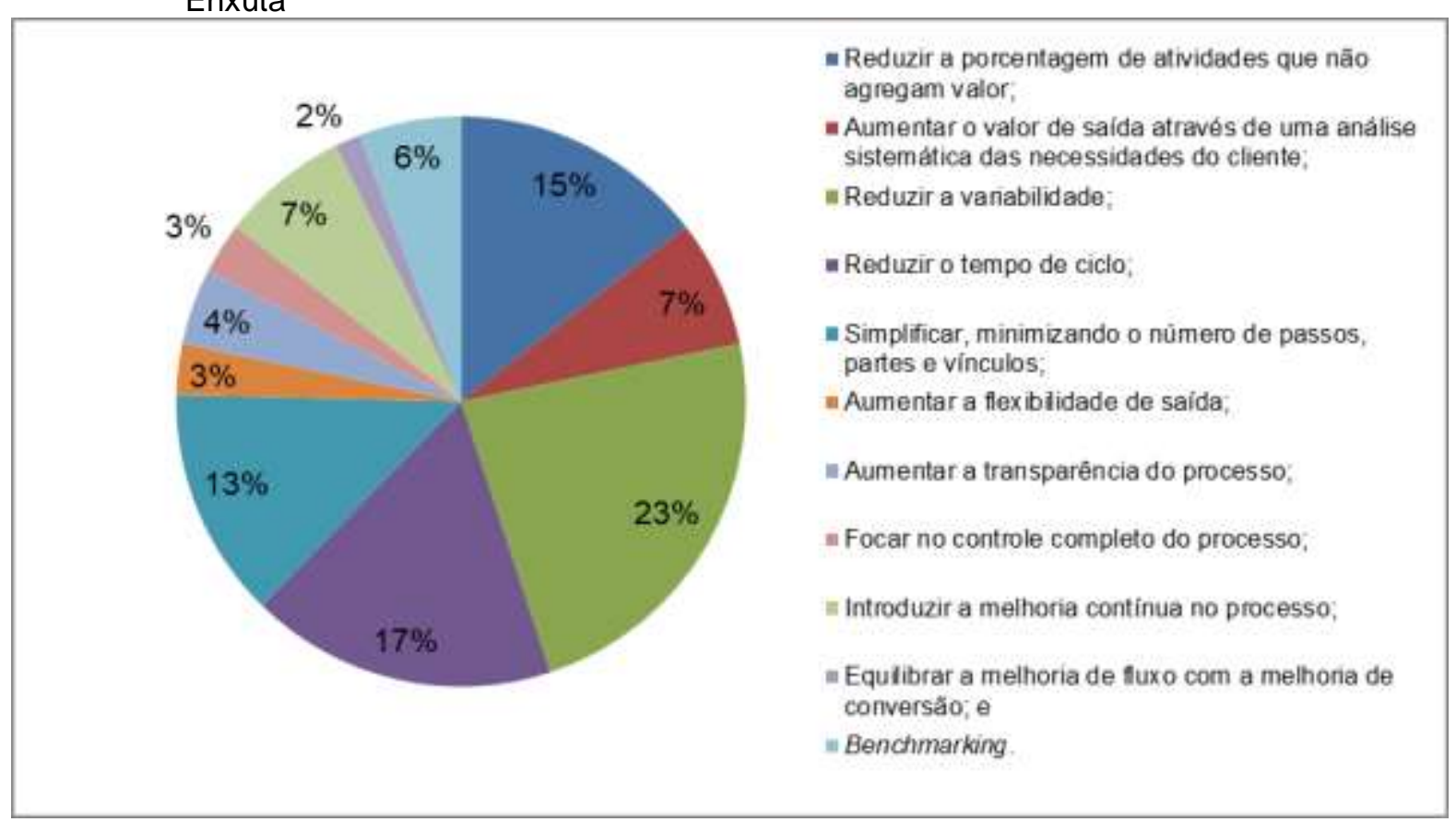

Fonte: Elaborado pelos autores 


\subsubsection{Atividades positivas (boas práticas) e negativas (pontos frágeis) em relação aos níveis hierárquicos do planejamento}

O gráfico da Figura 7 mostra a quantificação das boas práticas aplicadas nas obras e, consequentemente, o nível hierárquico a que correspondem dentro do planejamento. Através da análise do planejamento, é possível perceber que a maioria das atividades aplicadas nos canteiros das obras foram definidas no nível tático e no nível operacional. Da mesma forma, as atividades que permitiram a redução da variabilidade estavam relacionadas com os níveis tático e operacional, como, por exemplo, o uso de blocos paletizados e argamassa industrializada. Isso demonstra a importância das decisões tomadas durante essas fases do planejamento para o bom desempenho ou não de uma obra.

Em contraponto, o gráfico da Figura 8 relaciona as atividades negativas ou frágeis praticadas nas obras ao nível hierárquico do planejamento correspondente. Observa-se que também o nível hierárquico tático foi o que apresentou uma percentagem elevada de atividades negativas. Verifica-se, então, que esse nível hierárquico tem forte impacto no processo executivo, como era de se esperar, seja com atividades positivas que foram identificadas ou com atividades negativas que deveriam ser evitadas.

Figura 7 - Quantificação percentual das Boas práticas em relação aos Níveis hierárquicos do planejamento

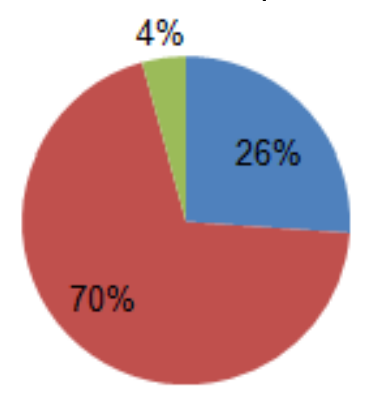

Fonte: Elaborado pelos autores
Figura 8 - Quantificação percentual das Atividades frágeis em relação aos Níveis hierárquicos do planejamento

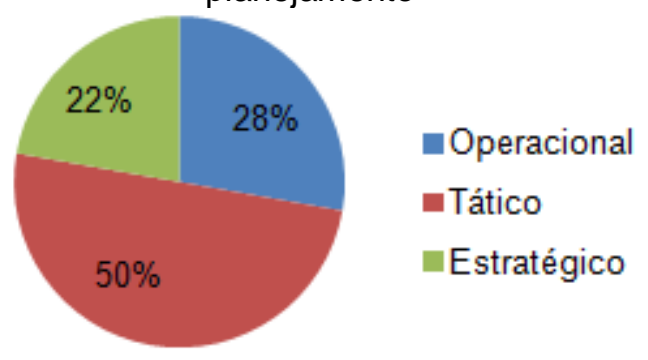

Fonte: Elaborado pelos autores

Segundo Koskela (2004), quando ocorre o planejamento informal há o aparecimento do making-do, pois é visto erroneamente como uma solução para a falta de planejamento adequado. Para o mesmo autor, uma das formas de reduzir 
perdas do tipo making-do é considerar a redução da principal causa das perdas, a variabilidade, na fase de planejamento.

\subsubsection{Atividades positivas (boas práticas) e negativas (pontos frágeis) em relação aos tipos de perdas}

Em termos do tipo de perda, o gráfico apresentado na Figura 9 mostra a quantificação das boas práticas aplicadas nas obras em relação aos tipos de perdas definidas por Shingo (1996b) e Koskela (2004) que foram evitadas por causa da aplicação dessas atividades. Observa-se que 37\% das perdas evitadas estavam relacionadas com o making-do. Este dado ratifica que as antecipações gerenciais reduzem o risco de uma interrupção no processo e perdas do tipo making-do (MESQUITA, 2014).

Figura 9 - Quantificação percentual das Boas práticas em relação aos tipos de perdas

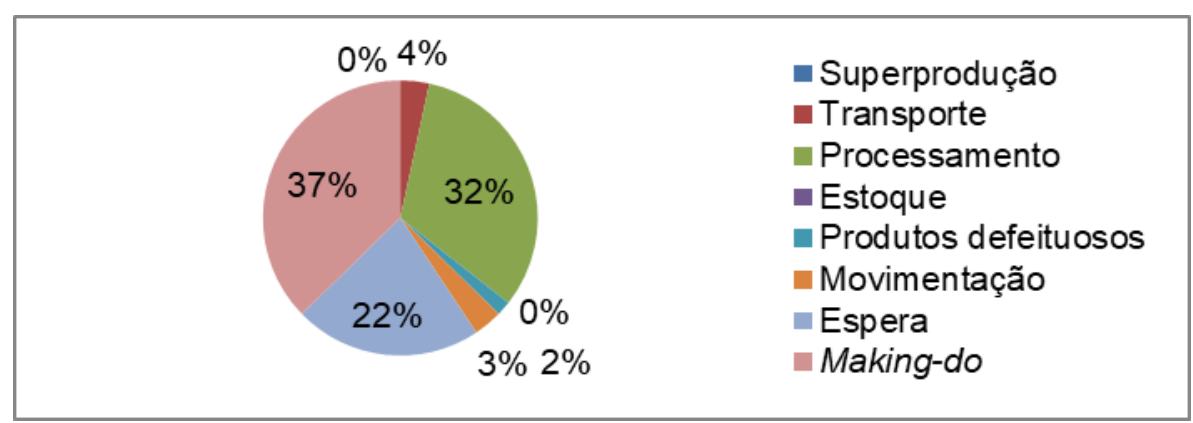

Fonte: Elaborado pelos autores

Por sua vez, o gráfico da Figura 10 demonstra a relação entre as atividades negativas ou frágeis praticadas nas obras e os tipos de perdas que ocorreram por consequência de sua aplicação. Percebe-se, a partir da análise do gráfico, que 51\% das perdas ocorridas foram do tipo making-do e que $16 \%$ foram do tipo produtos defeituosos. 
Figura 10 - Quantificação percentual das Atividades frágeis em relação aos tipos de perdas

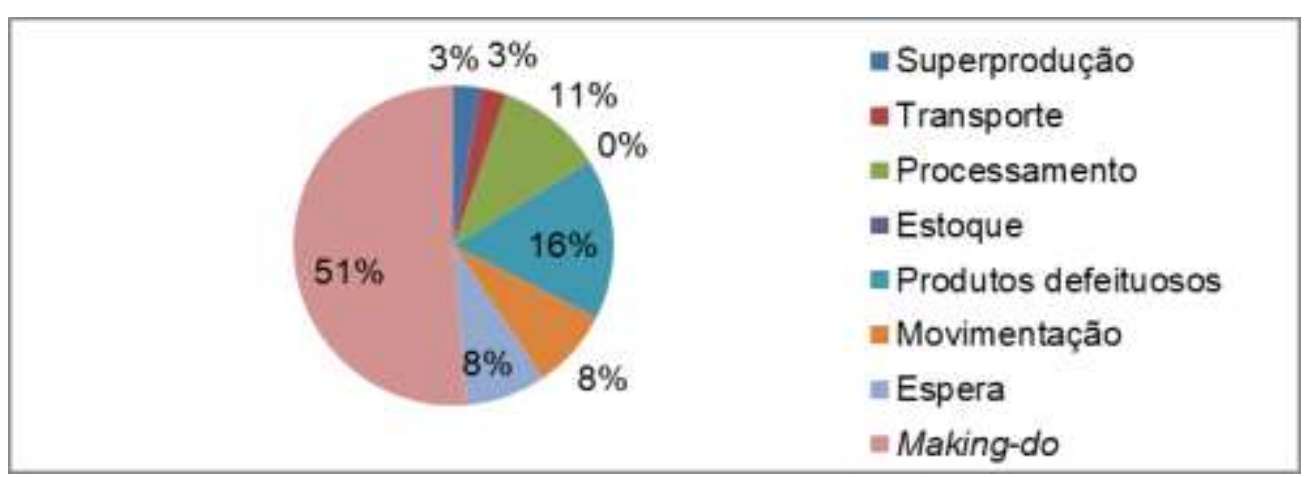

Fonte: Elaborado pelos autores

Comparando os gráficos das Figuras 9 e 10, verifica-se que as perdas por making-do foram exemplificadas em maior quantidade, tanto em termos de boas práticas como de pontos frágeis. Porém, os exemplos negativos ocorreram em quantidade superior aos positivos, o que requer maiores cuidados, de modo a minimizar, em campo, atividades desse tipo, que levam ao aumento da variabilidade.

Os dados apresentados na Figura 10 confirmam o que foi diagnosticado na Figura 6 , já que a variabilidade que ocorre na produção não disponibiliza uma entrada padrão e como consequência gera perdas do tipo making-do (KOSKELA, 2004). Ademais, para Isatto et al. (2000), a variabilidade, por causar a descontinuidade de fluxos de trabalho, tende a aumentar a parcela das atividades que não agregam valor.

Atenção deve ser dada também para evitar o recebimento e a aplicação de produtos defeituosos (16\%) e de falhas no processamento em si $(11 \%)$, o que impacta negativamente na redução da variabilidade, conforme já mencionado. Os percentuais aqui apresentados demonstram que a preocupação das empresas construtoras volta-se para as etapas finais (execução da alvenaria), em detrimento das etapas iniciais (recebimento de materiais).

\subsubsection{Atividades positivas (boas práticas) em relação à categoria de atividades facilitadoras}

$\mathrm{Na}$ Figura 11, foi apresentada a quantificação das boas práticas em relação às categorias de atividades facilitadoras propostas por Santos (2004). Percebeu-se que $54 \%$ delas pertenciam à categoria preparação do trabalho, mostrando que as 
boas práticas estão intimamente relacionadas à disponibilização de todos os recursos necessários para a execução do serviço no momento oportuno.

Figura 11 - Quantificação percentual das Boas práticas em relação às Categorias de atividades facilitadoras

\begin{tabular}{|c|c|}
\hline $\left.\begin{array}{c}5 \% \\
0 \% \\
0 \%\end{array}\right] \quad \begin{array}{l}0 \% 0 \% \\
9 \%\end{array}$ & $\begin{array}{l}\text { - Acesso } \\
\text { - Projeto } \\
\text { = Preparação do trabalho } \\
\text { - Conferência do trabalho } \\
\text { - Conflito espacial } \\
\text { - Sequenciamento } \\
\text { - Proteção dos Operários } \\
\text { - Proteção dos Processos } \\
\text { - Programação de obra }\end{array}$ \\
\hline
\end{tabular}

Fonte: Elaborado pelos autores

\subsubsection{Atividades negativas (pontos frágeis) em relação à categoria de problemas}

O gráfico apresentado na Figura 12 quantifica as atividades negativas ou frágeis segundo as categorias dos problemas apresentadas por Santos (2004). Após a análise do gráfico, observa-se que $42 \%$ das atividades frágeis pertencem à categoria preparação do trabalho, seguido de conferência do trabalho com $26 \%$.

Essa informação é bastante importante, pois mostra que a maioria dos problemas encontrados, assim como também as variabilidades percebidas durante a execução da obra, ocorrem por causa da ausência de itens necessários para a execução do serviço. Além disso, confirma a teoria de Koskela (2004), perda por making-do, que ocorre quando não se têm todos os recursos necessários para a execução de determinada tarefa, ou seja, os sete fluxos.

Figura 12 - Quantificação percentual das Atividades frágeis em relação às Categorias dos problemas

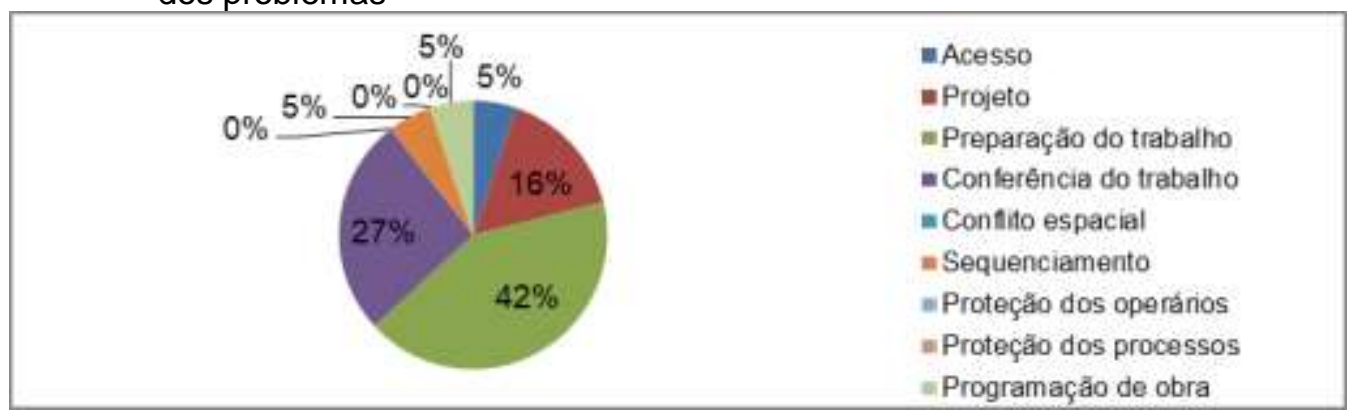

Fonte: Elaborado pelos autores

Revista Produção Online. Florianópolis, SC, v.17, n. 4, p. 1218-1248, 2017. 
Assim como para as demais análises realizadas, percebe-se, ao comparar as percentagens de pontos positivos e negativos, que os grupos, em ambas as Categorias, mais pontuados foram os mesmos. Neste caso, na categoria de preparação de trabalho, percebe-se uma oportunidade para a redução de variabilidade dos processos anteriores ao associá-lo com os itens da norma recebimento e armazenamento de blocos, requisitos antes do início da elevação e implantação.

Para os pontos negativos, a segunda categoria a ser destacada foi a de conferência do trabalho, que se relaciona com variabilidade no próprio processo e impacta os processos posteriores.

\subsubsection{Atividades positivas (boas práticas) e negativas (pontos frágeis) em relação aos sete fluxos}

O gráfico da Figura 13 apresenta a quantificação das boas práticas encontradas nas obras em relação aos sete fluxos de Koskela (2000). Das atividades aplicadas nas obras, destacam-se aquelas que estão relacionadas com os equipamentos ou ferramentas, representando 35\% das atividades. As atividades que permitiram a redução da variabilidade foram aplicadas na padronização de equipamentos e ferramentas, materiais e componentes. Decisões tomadas na etapa de projetos definiram atividades facilitadoras que também contribuíram para redução da variabilidade. Esse fato mostra que a ocorrência da redução da variabilidade é dependente da padronização e disposição dos elementos do kit completo antes do momento da execução do serviço.

Figura 13 - Quantificação percentual das Boas práticas em relação às Categorias dos sete fluxos

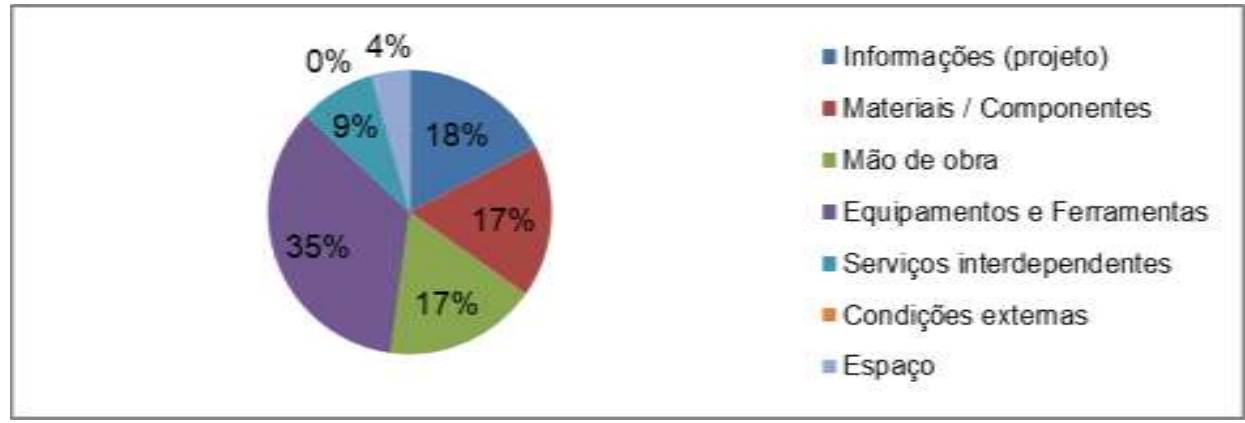

Fonte: Elaborado pelos autores 
O gráfico apresentado na Figura 14 apresenta a quantificação das atividades negativas ou frágeis praticadas nas obras em relação aos sete fluxos de Koskela (2000). O gráfico mostra que a maioria (35\%) das fragilidades encontradas nas obras está relacionada a variabilidades e defeitos nos materiais ou componentes, $29 \%$ correspondem a falhas ou falta de informações necessárias para a execução dos serviços de forma adequada e 18\%, a problemas relacionados aos equipamentos ou ferramentas.

Esses dados convergem para a mesma conclusão dos demais gráficos, de que há grande necessidade de aprimoramento do planejamento para que possa ser garantida a disponibilização de todos os elementos necessários para a produção de determinada atividade, no caso, a elevação de alvenaria de vedação.

Figura 14 - Quantificação percentual das Atividades frágeis em relação às Categorias dos sete fluxos

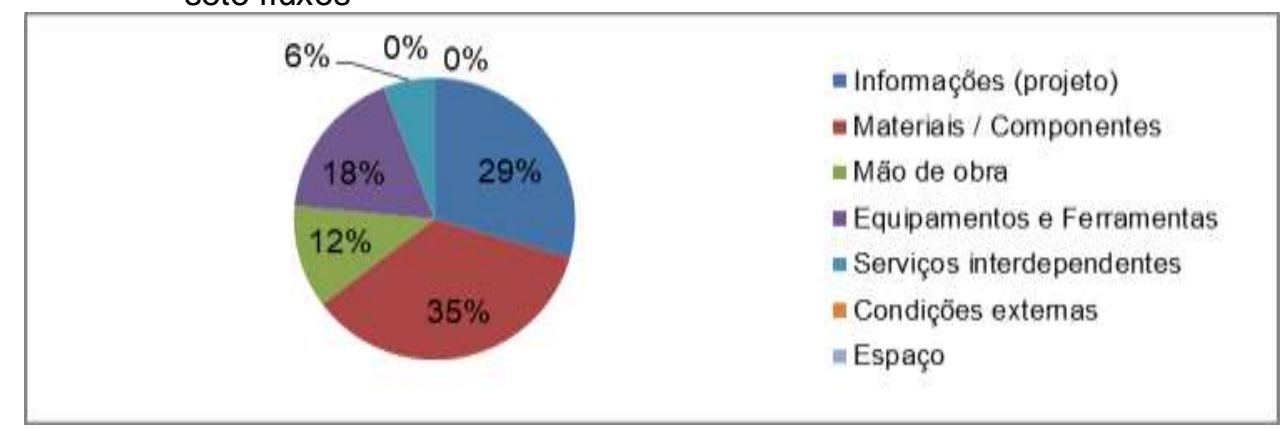

Fonte: Elaborado pelos autores

Embora os grupos mais pontuados tenham divergido com relação aos pontos positivos e negativos, no primeiro grupo (pontos positivos), os exemplos foram para a categoria equipamentos e ferramentas e, no segundo grupo, (pontos negativos) os exemplos foram para a categoria materiais / componentes. É certo que as categorias equipamentos e ferramentas, informações (projeto) e materiais / componentes foram as mais pontuadas, tanto em termos positivos como negativos, e merecem atenção para contribuir com a redução de variabilidade.

\section{CONSIDERAÇÕES FINAIS}

Como resultado da comparação entre os padrões estabelecidos pelas normas reguladoras da alvenaria estrutural, percebeu-se que grande parte das empresas não possuía conhecimento sobre as exigências para recebimento de bloco, como também para o armazenamento. Esse fato acarreta o aumento da variabilidade do 
material analisado - bloco - e também a redução da qualidade da alvenaria estrutural.

Após a análise da base de dados, quantificou-se que a maioria das boas práticas aplicadas nas obras, $23 \%$ delas, estava relacionada com o princípio da redução de variabilidade. Identificou-se também que essas boas práticas foram definidas durante o planejamento de nível tático e operacional. Esses dados confirmam que as decisões tomadas durante essas fases não cumprem um papel decisivo para o bom desempenho de uma obra.

Percebeu-se também que $37 \%$ das perdas evitadas por conta da aplicação das boas práticas durante o processo de produção de elevação de alvenaria estrutural estavam relacionadas com o making-do. Este item confirma a afirmação de Mesquita (2014) ao dizer que as antecipações gerenciais reduzem o risco de uma interrupção no processo e perdas do tipo making-do.

As boas práticas aplicadas nas obras pertenciam, em sua maioria (96\%), à categoria preparação do trabalho (pertencente ao planejamento tático e operacional), que se resume à disponibilização de todos os recursos necessários para a execução do serviço no momento oportuno. Essa informação apresenta a explícita relação entre os conceitos do kit completo e as boas práticas, já que as boas práticas são antecipações gerenciais que garantem a disponibilização de tudo que for necessário para a execução do serviço.

Por fim, as boas práticas que permitiram a redução da variabilidade foram aplicadas na padronização de equipamentos e ferramentas, materiais e componentes e também através de decisões na etapa dos projetos. Esse fato mostra que a ocorrência da redução da variabilidade é dependente da padronização e disposição dos elementos do kit completo antes do momento da execução do serviço. Também demonstra que as decisões tomadas durante a fase de projetos acarretam impactos significativos no que se refere à redução da variabilidade.

Assim como a maioria das boas práticas pertenciam à categoria preparação do trabalho, percebeu-se que a maioria das atividades frágeis também a essa mesma categoria, cerca de $42 \%$, seguido da categoria conferência do trabalho, $26 \%$. Esse dado destaca que, apesar de serem observados esforços aplicados durante a fase de preparação do trabalho por parte dos gestores das obras, ainda existem 
muitas falhas ocorridas durante essa fase, fase essa que garante a execução do serviço sem interrupções.

Ademais, $51 \%$ das atividades frágeis praticadas nas obras geraram perdas do tipo making-do. Essa informação corrobora o que foi afirmado anteriormente, já que a variabilidade existente durante a produção indisponiliza uma entrada padrão e, como consequência, gera perdas do tipo making-do, podendo causar descontinuidade de fluxos de trabalho que tende a aumentar a parcela das atividades que não agregam valor (ISATTO et al., 2000).

Semelhantemente às boas práticas, as atividades frágeis encontradas nas obras ocorriam devido a falhas presentes no planejamento tático e operacional. Além disso, 35\% das atividades frágeis estão relacionadas a variabilidades e defeitos nos materiais ou componentes ou por falta de informação. Esses dados convergem para a mesma conclusão dos demais gráficos, de que há grande necessidade de aprimoramento do planejamento para que possa ser garantida a disponibilização de todos os elementos necessários para a produção de determinada atividade, no caso, a elevação de alvenaria de vedação.

Percebeu-se também que as empresas ainda possuem dificuldade em aplicar os padrões estabelecidos para as atividades anteriores, ou seja, os requisitos antes do início da elevação e as atividades necessárias para a implantação, que é a marcação da alvenaria. Entretanto, as empresas têm cumprido a maioria dos itens relacionados à elevação da alvenaria e todos os itens que tratam de detalhes construtivos.

Conclui-se assim que as empresas têm cumprido grande parte dos requisitos referentes ao processo construtivo, porém têm deixado a desejar nos itens referentes aos processos anteriores.

Os resultados obtidos abordados nesse trabalho, serviram de base para as etapas posteriores resumidas na construção de uma ferramenta de gestão que auxiliasse os gestores de obras na implantação do kit completo na alvenaria estrutural e consequente redução de variabilidade. A ferramenta também permitiu ao gestor a possibilidade de realizar um planejamento tático de médio prazo adequado à realidade de cada obra. 


\section{REFERÊNCIAS}

ABNT. ASSOCIAÇÃO BRASILEIRA DE NORMAS TÉCNICAS. NBR 15270-1: componentes cerâmicos parte 1: blocos cerâmicos para alvenaria de vedação - terminologia e requisitos. Rio de Janeiro, 2005a. 11 p.

ABNT. ASSOCIAÇÃO BRASILEIRA DE NORMAS TÉCNICAS. NBR 15270-2: componentes cerâmicos parte 2: blocos cerâmicos para alvenaria estrutural - terminologia e requisitos. Rio de Janeiro, 2005b. 11 p.

ABNT. ASSOCIAÇÃO BRASILEIRA DE NORMAS TÉCNICAS. NBR 15270-3: componentes cerâmicos parte 3: blocos cerâmicos para alvenaria estrutural e de vedação - métodos de ensaio. Rio de Janeiro, 2005c. 27 p.

ABNT. ASSOCIAÇÃO BRASILEIRA DE NORMAS TÉCNICAS. NBR 15812-2: alvenaria estrutural - blocos cerâmicos parte 2: execução e controle de obras. Rio de Janeiro, 2010. $28 \mathrm{p}$.

ABNT. ASSOCIAÇÃO BRASILEIRA DE NORMAS TÉCNICAS. NBR 15961-2: alvenaria estrutural - blocos de concreto parte 2: execução e controle de obras. Rio de Janeiro, 2011. $35 \mathrm{p}$.

ABNT. ASSOCIAÇÃO BRASILEIRA DE NORMAS TÉCNICAS. NBR 6136: blocos vazados de concreto simples para alvenaria - requisitos. Rio de Janeiro, 2014. 10p.

BALLARD, G. The Last Planner System of Production Control. 2000. Thesis (Doctor) School of Civil Engineering, Faculty of Engineering, University of Birmingham. Birmingham. 2000.

BERNARDES, M. M. S. Desenvolvimento de um modelo de planejamento e controle da produção para micro e pequenas empresas da construção. 2001. Tese (Doutorado) Programa de Pós-Graduação em Engenharia Civil da Universidade Federal do Rio Grande do Sul. Porto Alegre. 2001.

BOGGIO, A. J. Um modelo de documentação da qualidade para a construção civil. In: Gestão da Qualidade na Construção Civil: uma abordagem para empresas de pequeno porte, cap.5, Porto Alegre, RS, 1995. p. 127-147, il.

CAMPOS, V. F. TQC: controle da qualidade total (no estilo japonês). Nova Lima: INDG Tecnologia e Serviços Ltda, 2004.

COELHO, C. B. T. Antecipações gerenciais para a inserção de atividades facilitadoras na execução de alvenaria de tijolos cerâmicos: análise dos relatos de agentes do processo. 2009, 119p. Dissertação (Mestrado) - Programa de Pós-Graduação em Construção Civil, Área de Gerenciamento. Universidade Federal do Paraná, Ponta Grossa, 2009.

FAZINGA, W. R. Particularidades da construção civil para implantação do trabalho padronizado. 2012, 157p. Dissertação (Mestrado em Engenharia de Edificações e Saneamento). Programa de Pós-Graduação em Edificações e Saneamento. Universidade Estadual de Londrina, Londrina, 2012. 
FIREMAN, M. C. T. Proposta de método de controle integrado produção e qualidade, com ênfase na medição de perdas por making-do e retrabalho. 2012. Dissertação

(Mestrado em Engenharia) - Programa de Pós-Graduação em Engenharia Civil, Universidade Federal do Rio Grande do Sul, Porto Alegre, 2012.

FIREMAN, M. C. T.; FORMOSO; C. T., ISATTO, E. L. Integrating production and quality control: monitoring making-do and unfinished work. In: ANNUAL CONFERENCE OF THE INTERNATIONAL GROUP FOR LEAN CONSTRUCTION, 21, 2013, Fortaleza.

Proceedings...Fortaleza, 2013. https://doi.org/10.13140/RG.2.1.1607.3767

FORMOSO, C. T.; SOMMER, L.; KOSKELA, L.; ISATTO E. L. An exploratory study on the measurement and analysis of making-do in construction sites. In: ANNUAL CONFERENCE OF THE INTERNATIONAL GROUP FOR LEAN CONSTRUCTION, 19., 2011, Lima. Proceedings... Lima. 2011.

FORMOSO, C. T.; SOMMER, L.; KOSKELA, L.; ISATTO, E. L. The identification and analysis of making-do waste: insights from two Brazilian construction sites. Ambiente Construído, Porto Alegre, v. 17, p. 183-197, july./sept. 2017.

http://dx.doi.org/10.1590/s1678-86212017000300170

FRANCO, L. S. Aplicação de diretrizes de racionalização construtiva para a evolução tecnológica dos processos construtivos em alvenaria estrutural não armada. 1992. 319p. Tese (Doutorado em Engenharia) - Escola Politécnica, Universidade de São Paulo, São Paulo. 1992.

GROSSKOPF, J. Boas práticas e descontinuidades na produção: da execução ao projeto de empreendimento complexo. 2013. Dissertação (Mestrado em Engenharia), Programa de Pós-Graduação em Engenharia Civil, Universidade Federal de Sergipe, 2013.

GOSSKOPF, J.; MENEZES, A.; SANTOS, D. G. Proposal of activities that facilitate work in order to avoid workflow interruptions caused by making-do. In: ANNUAL CONFERENCE OF THE INTERNATIONAL GROUP FOR LEAN CONSTRUCTION, 21 ${ }^{\text {st }}$, Fortaleza, Brazil, 2013. Proceedings... Fortaleza, 2013, p.719-728.

HAMZEH, F. R.; BALLARD, G.; TOMMELEIN, I. D. Improving construction workflow-the connective role of lookahead planning. In: ANNUAL CONFERENCE OF THE INTERNATIONAL GROUP FOR LEAN CONSTRUCTION, 16, Manchester, UK, 2008. Proceedings... Manchester, 2008, 12p.

HOPP, W. J.; SPEARMAN, M. L. Factory physics: foundations of manufacturing management. Boston: Irwin Mc Graw-Hill, 1996. 668p.

HOWELL, G. A.; BALLARD, G.; TOMMELEIN, I. Construction engineering-Reinvigorating the discipline. Journal of Construction Engineering and Management, v. 137, n. 10, p. 740-744, 2011.

HOWELL, G. A. New operating system for project management: consequences and opportunities. Journal of Construction Engineering and Management, v. 137, n. 10, p. 882-886, 2011.

ISATTO, E. L.; FORMOSO, C. T.; DE CESARE, C. M.; HIROTA, E. H.; ALVES, T. C. L. Lean construction: diretrizes e ferramentas para o controle de perdas na construção civil. Porto Alegre, SEBRAE/RS, 2000. Série SEBRAE Construção Civil, Vol. 5. 
ISATTO, E. L.; ZUCHETTI, M. Aplicação do mecanismo da função produção ao planejamento da produção seriada na construção. In: Encontro Nacional de Tecnologia do Ambiente Construído, 2014. p. 1327, Maceió. Anais... Maceió, 2014.

https://doi.org/10.17012/entac2014.519

KOSKELA, L. Application of the new production philosophy to construction. Technical Report no. 72. Center for Integrated Facility Engineering. Stanford University, 1992, 87p.

KOSKELA, L. Management of production in construction: a theoretical view. In: ANNUAL CONFERENCE OF THE INTERNATIONAL GROUP FOR LEAN CONSTRUCTION, 7, 1999, Berkeley. Proceedings... Berkeley, 1999.

KOSKELA, L. An Exploration Towards a Production Theory and its Application to Construction. 2000. 296f. Thesis (Doctor). Espoo, Finlândia: VTT. 2000.

KOSKELA, L. Making-do: the eighth category of waste. In: ANNUAL CONFERENCE ON THE INTERNATIONAL GROUP OF LEAN CONSTRUCTION, 12th, Elsinore, Denmark. 2004. Proceedings... Denmark, 2004, 10p.

LEÃO, C. F. Proposta de modelo para controle integrado da produção e da qualidade utilizando tecnologia de informação. 2014. 179p. Dissertação (Mestrado em Engenharia), Programa de Pós-Graduação em Engenharia Civil, Universidade Federal do Rio Grande do Sul, Porto Alegre, 2014.

LEÃO, C. F.; ROCHA, G. S.; FORMOSO, C. T. Perdas por making-do identificadas no canteiro de obras de um condomínio horizontal de baixa renda. In: CONGRESSO DE SISTEMAS LEAN, IV, 2014, Porto Alegre. Anais.... Porto Alegre: UFRGS/PPGEP, 2014a. p. 394-410.

LEÃO, C. F.; FORMOSO, C. T.; ISATTO, E. L. Integrating Production and Quality Control with the Support of Information Technology. In: ANNUAL CONFERENCE OF THE INTERNATIONAL GROUP FOR LEAN CONSTRUCTON, 22, 2014b, Oslo. Proceedings... Oslo, 2014b.

LEÃO, C. F.; ISATTO, E. L.; FORMOSO, C. T. Proposta de modelo para controle integrado da produção e da qualidade com apoio da computação móvel. Ambiente Construído, Porto Alegre, v. 16, n. 4, p. 109-124, out./dez. 2016. ISSN 1678-8621.

http://dx.doi.org/10.1590/s1678-86212016000400108

LIKER, J; HOSEUS, M. A cultura Toyota: a alma do modelo Toyota. Porto Alegre, RS: Bookman, 2009. 576p.

MACHADO, R. L. A sistematização de antecipações gerenciais no planejamento da produção de sistemas da construção civil. 2003. Tese (Doutorado) - Programa de Pósgraduação em Engenharia de Produção da Universidade Federal de Santa Catarina. Florianópolis. 2003.

MESQUITA, V. F. de. Desenvolvimento de jogo didático para tornar prático o uso das atividades que contribuem para a melhoria de processo: elevação da alvenaria estrutural. 2014. 174p. Dissertação (Mestrado em Engenharia), Programa de PósGraduação em Engenharia Civil, Universidade Federal de Sergipe, 2014. 
MOURA, R. S. L. M.; HEINECK, L. F. M. Linha de Balanço - Síntese dos princípios de produção enxuta aplicados à programação de obras? In: ENCONTRO NACIONAL DE TECNOLOGIA DO AMBIENTE CONSTRUIDO, 2014, Maceió. Anais... Maceió, 2014.

MORGAN, J. M. Sistema Toyota de desenvolvimento de produto: integrando pessoas, processo e tecnologia. Trad. Rubenich. Porto Alegre, RS, Bookman, 2008. 391 p.

NASCIMENTO, R. S.; SANTOS, D. G. A amostragem do trabalho como ferramenta de diagnóstico para a aplicação dos conceitos da construção enxuta. In: SIMPÓSIO BRASILEIRO DE GESTÃO E ECONOMIA DA CONSTRUÇÃO, 8ํ, Salvador, 2013. Anais... Salvador, 2013, 14p.

NESENSOHN, C.; BRYDE, D.; OCHIENG, E; FEARON D.; HACKETT, V. Assessing Lean Construction Maturity. In: ANNUAL CONFERENCE ON THE IGLC, 22th, 2014, Oslo, Norway. Proceedings... Oslo, Norway. 2014. pp. 1157-1168.

OHNO, T. O sistema Toyota de Produção: além da produção em larga escala. Porto Alegre, RS: Bookman, 2004. 149 p.

RONEN, B. The complete kit concept. International Journal of Production Research, London, v. 30, n. 10, p. 2457-2466, Oct. 1992.

SACKS, R.; RADOSAVLJEVIC, M.; BARAK, R. Requirements for building information modeling based lean production management systems for construction. Automation in Construction, v. 19, n. 5, p. 641-655, ago. 2010.

SANTOS, A. dos; POWELL, J. A.; SARSHAR, M. Evolution of management theory: the case of production management in construction. Management Decision, 2002a, Vol. 40 Iss: 8 pp. $788-796$.

SANTOS, A. dos, FORMOSO, C. T., TOOKEY, F. E. Expanding the meaning of standardisation within construction processes. The TQM Magazine, v. 14, n. 1, 2002b, p.2533.

SANTOS, D. G. Modelo de Gestão de Processos na Construção Civil para Identificação de Atividades Facilitadoras. 2004. Tese (Doutorado) - Programa de Pós-Graduação em Engenharia de Produção da Universidade Federal de Santa Catarina. Florianópolis. 2004.

SANTOS, D. G. Checklist sobre execução de alvenaria estrutural. 2008. Nota de aula. Disciplina Gerenciamento de Empreendimentos. Curso de Pós-Graduação Lato Sensu em Construção Civil. Universidade Federal de Sergipe. São Cristóvão. 2008.

SANTOS, P. R. R.; SANTOS, D. G. Investigação de perdas devido ao trabalho inacabado e o seu impacto no tempo de ciclo dos processos construtivos. Ambiente Construído, Porto Alegre, v. 17, n. 2, p. 39-52, abr./jun. 2017. ISSN 1678-8621.

http://dx.doi.org/10.1590/s1678-86212017000200145

SHINGO, S. Sistemas de produção com estoque zero: o sistema Shingo para melhorias contínuas. Porto Alegre: Artes Médicas, 1996a. 380p.

SHINGO, S. O Sistema Toyota de produção do ponto de vista da engenharia de produção. Porto Alegre: Artes Médicas, 1996b. 291p. 
SOMMER, L. Contribuições para um método de identificação de perdas por improvisação em canteiros de obras. 2010. 150p. Dissertação (Mestrado em Engenharia), Programa de Pós-Graduação em Engenharia Civil, Universidade Federal do Rio Grande do Sul, Porto Alegre, 2010.

TONIN, L. A. P.; SCHAEFER, C. O. Diagnóstico e Aplicação da Lean Construction em Construtora. Iniciação Científica CESUMAR - jan./jun. 2013, v. 15, n. 1, p. 23-31.

YIN, R. K. Estudo de caso: planejamento e métodos. 2ed. Porto Alegre: Bookman, 2001.

$$
\text { (c) (7) }
$$

Artigo recebido em 07/08/2016 e aceito para publicação em 05/10/2017

DOI: http://dx.doi.org/10.14488/1676-1901.v17i4.2551 